\author{
José Carlos Salcedo Hernández y Antonio-José Campesino Fernández \\ Departamento de Construcción y Departamento de Arte y Ciencias del Territorio \\ Universidad de Extremadura. Cáceres

\section{Marina Isla de Valdecañas (Cáceres): de proyecto de interés regional a liquidación por derribo}

\section{RESUMEN}

El complejo turístico Marina Isla de Valdecañas, en el extremo oriental de la provincia de Cáceres, es un dislate estrella de planificación urbanística, patrimonial y turística, resultado de la incompetencia de las administraciones públicas extremeñas, que lo acogieron y aprobaron como PIR, y del ecologismo antitodo, incapaz de entender la sostenibilidad social y económica del territorio extremeño.

\section{RÉSUMÉ}

Marina Isla de Valdecanas (Cáceres): de projet d'interet regional à dégagement pour la démolition.- Le resort Marina Isla de Valdecañas, à l'extrémité orientale de la province de Cáceres, est une star de l'absurdité la planification urbaine, le patrimoine et le tourisme, le résultat de l'incompétence du Gouvernement d'Estrémadure, qui l'a accueilli et approuvé comme PIR, environnementalisme et anti-tout, incapable de comprendre la durabilité sociale et économique du territoire de frontière.

\section{EL TERRITORIO}

$E$ ntre 1957 y 1963, Hidroeléctrica Española construyó el embalse de Valdecañas en la cuenca del Tajo, retenido por una presa de bóveda de $100 \mathrm{~m}$ de base y 300 de coronación, dotado de tres turbinas reversibles y potencia total instalada de $225.000 \mathrm{~kW}$, capaz de producir mil millones de $\mathrm{kW} / \mathrm{h}$ anuales con la central de bombeo reversible. Fue inaugurado por Franco, su esposa y varios ministros el 28 de junio de 1965, como recogió puntualmente el No-

\section{AbSTRACT}

Marina Isla de Valdecañas (Cáceres): from project of regional interest to demolition sale.- The resort Marina Isla de Valdecañas, at the eastern end of the province of Cáceres, is an absurdity star urban planning, heritage and tourism, the result of the incompetence of the Government of Extremadura, that welcomed and approved as PIR, environmentalism and anti-everything, unable to understand the social and economic sustainability of the frontier territory.

$$
\text { Palabras Clave/Mots clé/Keywords }
$$

Turismo, patrimonio, planeamiento, proyecto de interés regional, ilegalidad urbanística.

Tourisme, patrimoine, planification, projet d'interet regional, illegalite urbaine.

Tourism, heritage, planning, project of regional interest, urban illegality.
$D o^{1}$. La tecnología punta, las macrocifras faraónicas y las inauguraciones triunfales encubrían siempre el reverso de la moneda (bajo la presunta cantinela de obra de utilidad pública). Las aguas del embalse anegaron 7.178 hectáreas de superficie; inundaron los pueblos de Talavera la Vieja y Talaverinos (obligando al desalojo de unos dos mil ha-

\footnotetext{
${ }^{1}$ No-Do del 28 de junio de 1965. <http://www.rtve.es/filmoteca/no-do/not$1173 / 1476289>$
} 


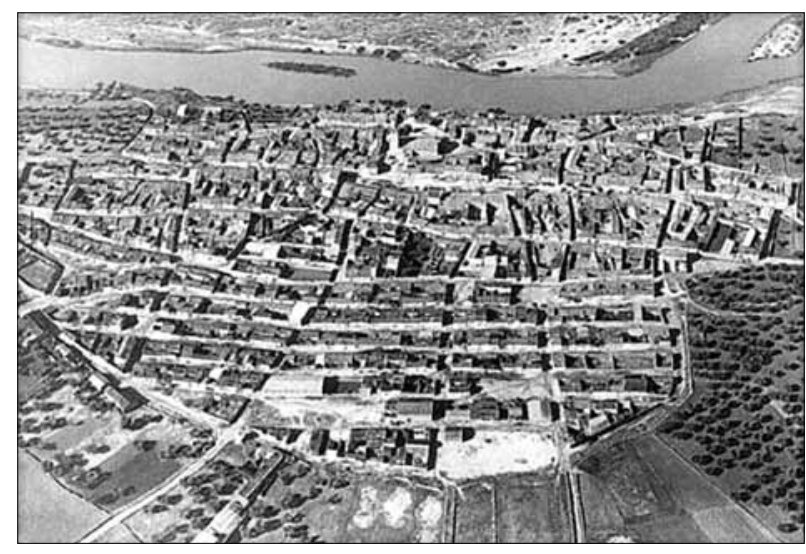

FIg. 1. Imagen de Talavera la Vieja antes de la inundación por el embalse de Valdecañas. Fuente: Dirección General de Patrimonio, Gobex.

bitantes, a su realojo en los poblados de colonización del valle del Tiétar o forzándolos a la emigración); sumergieron patrimonio tan notable como los restos arqueológicos de la Augustobriga romana (Talavera la Vieja), ubicada a la derecha del Tajo sobre la calzada principal de Emérita Augusta (Mérida) a Caesarobriga (Zaragoza), quedando como mudos restos de la antigua villa las columnas del templo de Los Mármoles, descontextualizadas y trasladadas en 1963 al borde del embalse, junto a la carretera CC173, de Bohonal a Navalmoral, en el km 53,7; hicieron desaparecer dólmenes neolíticos, y cortaron vías pecuarias y redes camineras, con transformaciones paisajísticas e impactos ambientales sin cuento.

En la cola del embalse quedó una pequeña isla desierta de 134,5 ha, un erial a pastos sin valor agropecuario alguno, con encinas aisladas y eucaliptos, a caballo entre los términos municipales cacereños de El Gordo y Berrocalejo. Pese al nulo valor patrimonial del entorno transformado, la Junta de Extremadura decidió en enero de 2005, sin fundamento razonado alguno, declarar las 7.178 ha del embalse de Valdecañas zona de especial protección de aves (ZEPA) y solicitar a la Unión Europea su inclusión en la Red Natura 2000, para satisfacer las demandas ecologistas. Resultó políticamente rentable apuntarse al ecologismo, con imprudente desconocimiento de su trascendencia futura, por sus limitaciones sobre la población y otros usos no agroganaderos del suelo rústico.

\section{EL PROYECTO TURÍSTICO}

En 2005, el Grupo Empresarial Marina Isla Antilla, S. A., creado el 22 de enero de 2003 y radicado en Sevi-

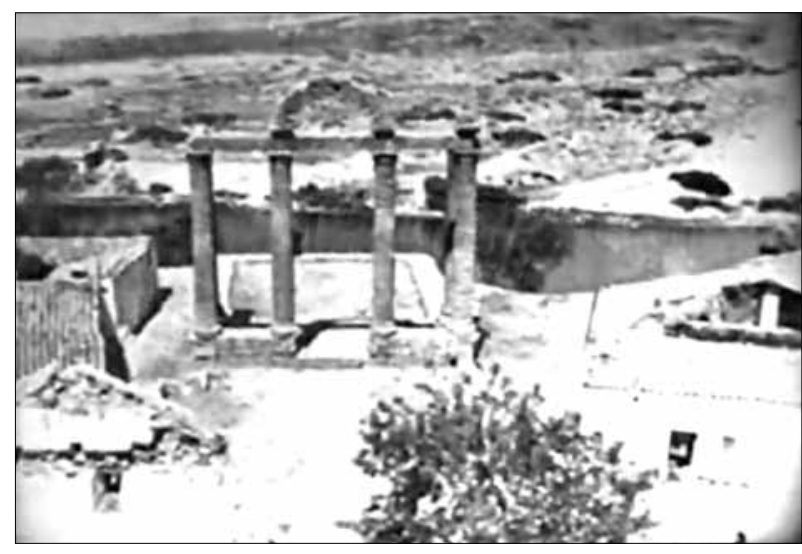

FIG. 2. Restos del templo romano de Los Mármoles, en Talavera la Vieja, antes de su traslado. Fuente: No-Do.

lla, de solvente currículum en sus promociones turísticas (Marina Isla Antilla, Hotel Oasis Islantilla, Complejo Turístico de El Rompido - Cartaya-, puerto deportivo Río Piedras), compró a dos propietarios privados la isla de Valdecañas. Sobre ella, el equipo de Miguel Ángel Gea \& Arquitectos proyectó un resort de lujo (campo de golf, hoteles y villas), eufemísticamente denominado «Complejo Turístico, de Salud, Paisajístico y de Servicios Marina Isla de Valdecañas», en el entorno privilegiado de las 7.178 ha del embalse, enmarcadas por la sierra de Gredos a poniente, Las Villuercas al sureste y el Parque Nacional de Monfragüe al sur. Enclave de excelente renta de situación, a $175 \mathrm{~km}$ de Madrid y a 90 minutos del aeropuerto internacional de Madrid-Barajas, y con accesibilidad refrendada por la Autovía de Extremadura (A-5, km 163) y por la línea del futuro AvE Madrid-Lisboa.

El objetivo era trasladar al interior el modelo de lujo (golf más sol y playa) del litoral, materializando una superficie edificada de $119.700 \mathrm{~m}^{2}$, en $\operatorname{los} 1.336 .017 \mathrm{~m}^{2}$ de superficie de la isla, con la creación de cuatrocientos empleos en la fase de construcción y 180 en la de explotación.

El complejo turístico contaba inicialmente con campo de golf de 18 hoyos, ubicado en el centro y borde oriental y considerado el mejor de la zona centro; dos hoteles, uno de cuatro estrellas con cien habitaciones de la cadena Husa Golf (todavía en funcionamiento) y otro Hotel Medical-Spa, de cinco estrellas, ubicado en la punta meridional, aún a medio construir y detenido por imperativo legal; zona residencial con trescientas villas unifamiliares de lujo, en bancales, siguiendo curvas de nivel, para disfrutar todas ellas de las vistas al embalse, con superficies entre $270 \mathrm{~m}^{2}$ y $600 \mathrm{~m}^{2}$, en parcelas de $800 \mathrm{~m}^{2}$; bal- 


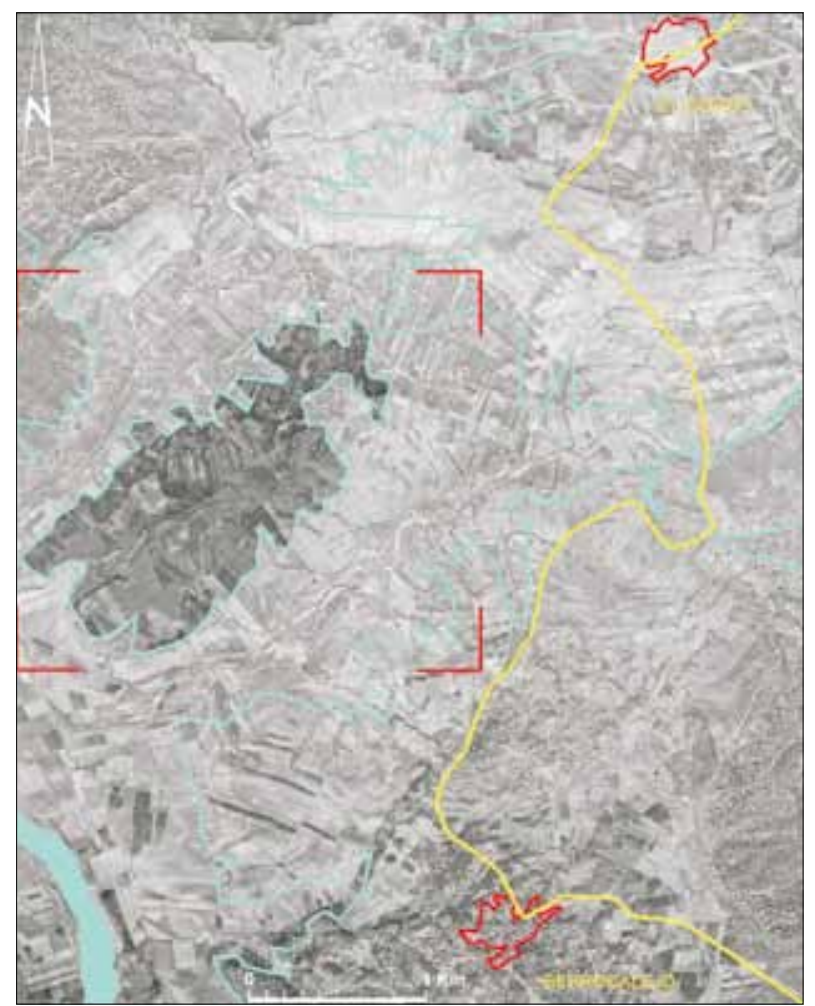

FIG. 3. Sobre la fotografía anterior a la inundación del embalse se han destacado los núcleos de El Gordo (al norte) y Berrocalejo (al sur), sus carreteras de acceso y el río Tajo. Se ha restituido el contorno del embalse, que delimitó la zona inundada posteriormente y la isla, objeto de estudio. En 1956 no hay cultivos ni bosques en la zona, sino «erial a pastos». Elaboración propia, sobre el fotograma aéreo del vuelo americano (1956), original a E. 1:33.000. Fuente: Instituto Geográfico Nacional (IGN).

neario con sesenta suites; ciento cincuenta apartamentos de dos dormitorios de $105 \mathrm{~m}^{2}$ con terraza de $40 \mathrm{~m}^{2}$; varias plazas privadas de aparcamiento por villa; dotación de buggies eléctricos privados por vivienda y públicos para desplazamientos por el campo de golf y el complejo; dársena náutica y puerto deportivo para atraques al norte de la isla; piscinas con chiringuito y playa artificial con zona lagunar represada para mantener constante el volumen de agua y no depender de las oscilaciones de nivel del embalse; centro de convenciones; zonas comerciales; carretera de acceso al complejo, que transforma la isla en península, con carriles para peatones y bicicletas; plantación de 4.500 árboles; mejora de las redes eléctricas, potabilizadora de agua y depuradora de aguas residuales.

Toda una profusión de instalaciones de alta calidad, pensadas para satisfacer demandas múltiples de tipologías turísticas (individual y de empresa, golf, náutica, caza, naturaleza, salud, congresos y otros eventos), apro-

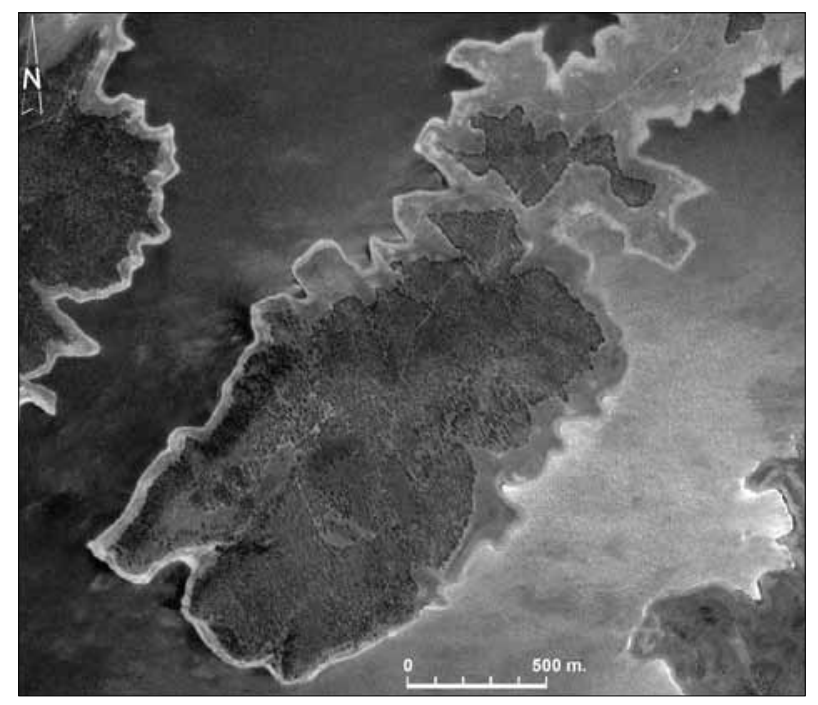

FIG. 4. Fotografía aérea anterior a la construcción de la urbanización, fecha de 1984. Vegetación de monte bajo con pies aislados de eucaliptos de repoblación. Fuente: IGN. Original a E. 1:30.000.

vechando los valores naturales, paisajísticos y medioambientales de la isla, del embalse y de los privilegiados entornos patrimoniales de la sierra de Gredos y del Parque Nacional de Monfragüe.

\section{INSERCIÓN EN EL PAISAJE}

La urbanización ha sido analizada desde el nivel del agua y desde el aire. El «perfil bajo» de las edificaciones no altera la silueta de la isla. Las edificaciones no ocupan ni el nivel de la orilla ni el nivel de coronación. El primero (de acceso público como zona de servidumbre legal) está ocupado por vegetación y sendas perimetrales, manteniéndose algunos eucaliptus de la repoblación del embalse. En el segundo se han respetado los quercus y se ha procedido a la plantación del arbolado de la urbanización (4.500 árboles). El criterio de diseño y articulación de las zonas y del viario en el proyecto de urbanización ha sido pensado para producir el menor impacto visual.

\section{VIARIO}

En la Fig. 11 se describen la urbanización y posteriormente la edificación. El viario articulador de la isla parte de un enlace con la carretera de El Gordo a Berrocalejo (CC-V-33). Penetra en la isla (convertida en península, precisamente por este vial) y tras pasar por el acceso y 
FIG. 5. Embalse de Valdecañas y núcleos de población de El Gordo, Berrocalejo, Bohonal de Ibor y Peraleda de la Mata. Fuente: mapa

E: 1:50.000 (escala original) del IGN, 2007. Se ha enmarcado la «isla» del embalse de Valdecañas.

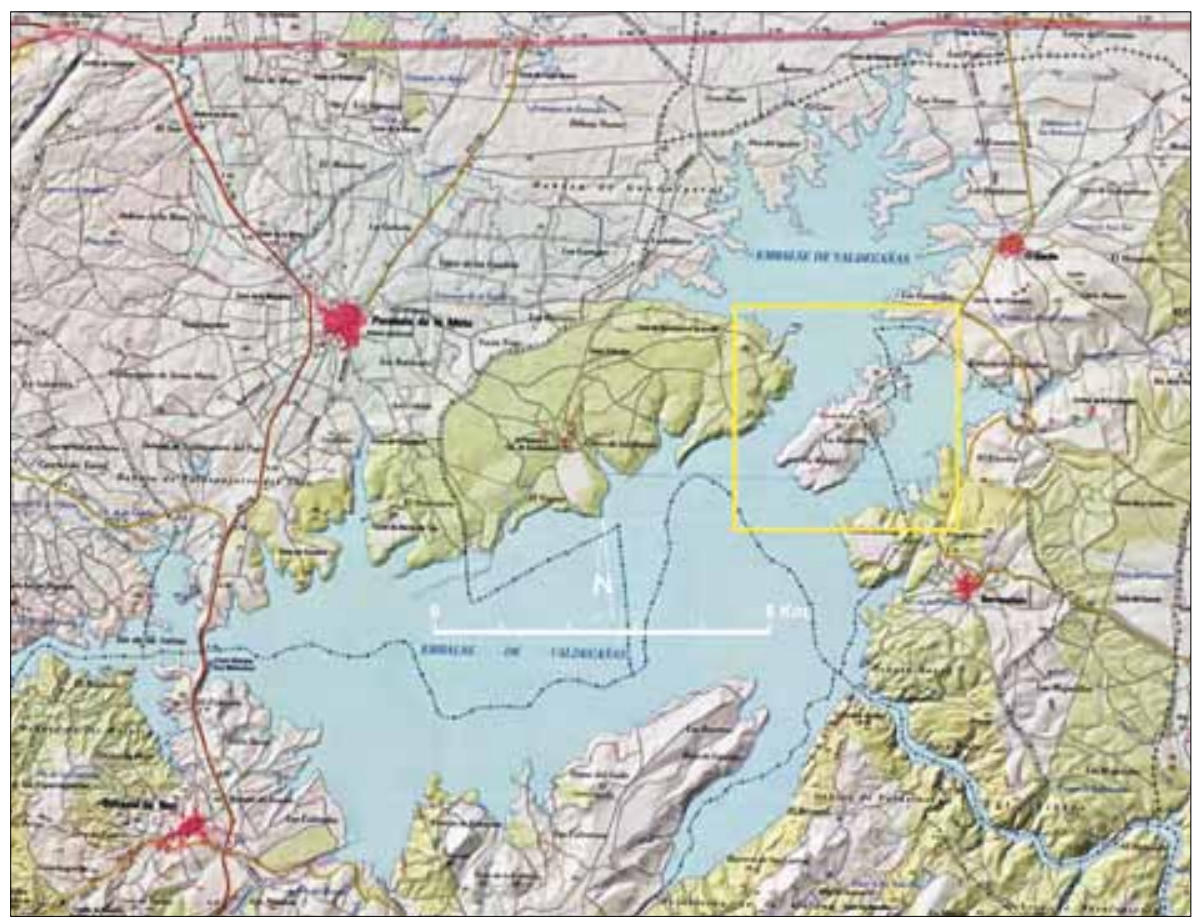

zona deportiva, conecta las diferentes zonas de la urbanización con las mínimas ramificaciones posibles y sin ocupar la parte alta de la isla, con un discurso a media ladera. El trazado de la planta es totalmente orgánico, adaptado a la topografía, sin líneas rectas ni mallas ortogonales.

\section{ZONIFICACIÓN}

Las villas se reparten en tres zonas: borde sur, borde noroeste y parte alta de la isla. Las dos primeras zonas están completamente edificadas y la tercera ha quedado paralizada tras la sentencia judicial. Las casas son unifamiliares y se distribuyen en hileras equidistantes (dos o tres) de parcelas adosadas, abancaladas, de manera que el aterrazamiento permite las vistas hacia el agua y al horizonte desde las situadas a más cota, sobre las situadas a nivel inferior, y sin interferir con las partes bajas (nivel de servidumbre del agua) ni con las partes altas (para no alterar el perfil de la isla).

Los dos hoteles se sitúan relativamente juntos y próximos a la ensenada en la que se encuentran las piscinas. Al hotel compacto de tres alturas y cuatro estrellas, que mantiene en funcionamiento la cadena Husa Golf, se accede desde el vial principal por situarse en la parte más elevada, con vistas lejanas. Para el segundo hotel, de cinco estrellas, con apartamentos individuales aterrazados al nivel del agua, se eligió la punta meridional, la más reservada y de mejores vistas, pero su construcción ha quedado en estructura, paralizada en cumplimiento de las sentencias judiciales.

La zona de piscinas se ha diseñado en forma de trazados orgánicos, vinculados a la vaguada abierta al embalse. Esta ensenada se ha cerrado con un dique artificial para mantener constante el nivel del agua, creando una playa artificial.

La zona perimetral de la isla corresponde al camino de servidumbre, que se puede recorrer en su conjunto, sin interferir con los anteriores espacios. Incorpora el arbolado existente de la isla (zonas verdes) y a su vez permite el acceso a distintas zonas: hotel, piscinas, dos ámbitos de casas, campo de golf y pantalán náutico.

El campo de golf de 18 hoyos ocupa básicamente las dos vaguadas de la isla y su lado oriental. Está bordeado por la zona de servidumbre de la orilla. Por su configuración (como «negativo» del viario principal), desde sus sendas peatonales se puede acceder a las distintas zonas, a través del viario principal y del hotel.

La zona deportiva, a la entrada de la urbanización, engloba los campos de futbol, pistas polideportivas y pistas de tenis y pádel, con su edificio anexo. Está pensada 


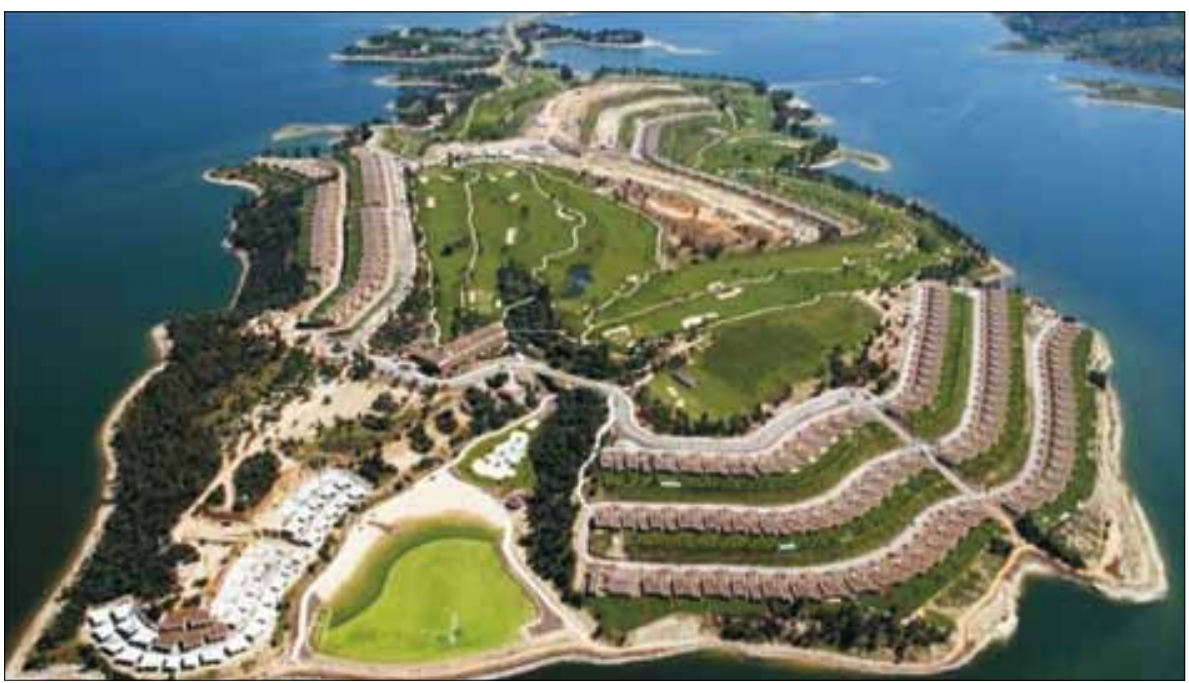

FIG. 6. Vista aérea del complejo turístico Marina Isla de Valdecañas. Fuente: empresa Marina Isla de Valdecañas, S. L. $<w w w . i s l a v a l d e c a n a s . c o m>$.

para la práctica de deportes, sin interferir en el funcionamiento de la urbanización, de manera que podría ser utilizada para competiciones regionales. La dársena náutica se sitúa en la orilla norte con acceso al pantalán de atraques mediante vehículos eléctricos.

El viario principal se reduce a la zona trazada en color rojo sobre la Fig. 11, que es el mínimo posible para dar acceso a todas las zonas. Consta de dos carriles y dos amplias zonas peatonales a los lados, una pavimentada y otra en forma de sendas de tierra. La sección se completa con abundante vegetación. Los enlaces se realizan por glorieta y el viario principal termina también en glorietas de las que parte el viario secundario que lleva en peine a cada parcela. El viario secundario está realizado con pavimento de mosaico, o con tierra y desde él los vehículos eléctricos acceden a todos los puntos de la isla. El diseño está pensado para el mínimo empleo de vehículos a motor y cada casa (y los usuarios del hotel) cuentan con vehículos eléctricos. De tal forma que los vehículos a motor que llegan a la isla se aparcan en garaje o delante del hotel y el tránsito por la isla se realiza por calles peatonales, viales de tráfico rodado de acceso a las viviendas y por el propio campo de golf, con los vehículos eléctricos.

\section{Características de la uRbanización}

Tanto los edificios de los hoteles como las villas y edificios auxiliares pertenecen a la tipología más moderna de las promociones del litoral español en los últimos años. Formalmente son volúmenes cúbicos, comercialmente atractivos, de colores claros y terrosos, que pro- ducen poco impacto visual, cubiertos en sus perfiles por arbolado. Pese a su precio final, son constructivamente bastante económicos, al estar realizados estandarizando soluciones constructivas, para generar el máximo beneficio empresarial.

Las villas son aisladas en su parcela, de una planta y con cubiertas planas de grava de leve pendiente para minorar el impacto visual. Tienen garaje y aparcamientos en fachada, están separadas de los linderos laterales, con retranqueo respecto a la fachada de acceso y con un jardín en el alzado interior. Este jardín dirige las visuales hasta el horizonte, de manera que el bancal inferior de casas no oculta las visuales hacia la lámina de agua. Hay varias tipologías en cuanto a los volúmenes edificados: la casa tipo tiene $255 \mathrm{~m}^{2}$ construidos $\left(222 \mathrm{~m}^{2}\right.$ de techo y un porche de $33 \mathrm{~m}^{2}$ ); existe un tipo más compacto, y otro en el que los volúmenes se separan, dejando un espacio interior a modo de patio abierto ajardinado. Cuentan con porches y pérgolas exteriores. Las que disponen de piscina, la sitúan en la zona posterior de la parcela.

\section{EL DISLATE TERRITORIAL, URBANÍSTICO Y AMBIENTAL}

La inversión inicial de doscientos millones de euros y la creación de empleos estables sedujeron fácilmente a la Junta de Extremadura, a su presidente, Juan Carlos Rodríguez Ibarra, y al consejero de Economía y Turismo, Manuel Amigo, así como a los mini-municipios regresivos de El Gordo (390) y Berrocalejo (126 habitantes), que intuyeron la llegada de la gallina de los huevos de 


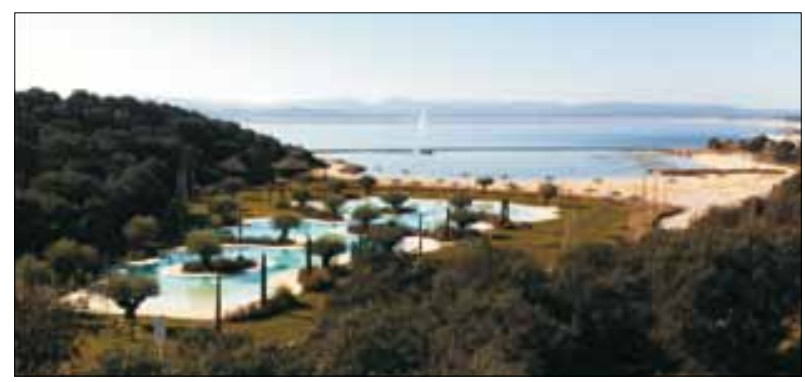

FIG. 7. Piscinas de la urbanización, con forma orgánica, integradas en una ensenada de la isla. Fuente: A.-J. Campesino.

oro. La Agencia Extremeña de la Vivienda, el Urbanismo y el Territorio (con su presidente, el arquitecto Javier Corominas Rivera) y la Dirección General de Medio Ambiente dieron informe inicial favorable al anteproyecto el 24 de enero de 2006 , a la espera de que la empresa promotora presentara el proyecto final, para su evaluación ambiental y tramitación urbanística definitiva.

Como el fin justificaba los medios, a petición de los ayuntamientos (13-10-2005) y tras la audiencia a los mismos (7-11-2005), la Junta de Extremadura por decreto 55/2007, de 10 de abril, aprobó el Proyecto de Interés Regional (PIR) Marina Isla de Valdecañas, con el objetivo de reclasificar y recalificar los terrenos de la isla para la construcción del complejo turístico. Y lo hicieron sin supeditación alguna, como era preceptivo, ni a las Directrices de Ordenación Territorial (aún por redactar) ${ }^{2}$ ni al Plan Territorial del Campo Arañuelo (entonces en redacción), al que estaban adscritos los municipios de El Gordo y Berrocalejo, y que obtendría aprobación definitiva por decreto 42/2008, de 21 de noviembre (DOE, núm. 230 de 27-11-2008). La presunta ordenación del territorio, al revés.

La Ley del Suelo y Ordenación Territorial de Extremadura (LSOTEX) otorga a los PIR el rango de instrumento de ordenación territorial, situándolos en la difusa frontera de la planificación territorial y urbanística, pero prevalente sobre esta última ${ }^{3}$. Sobre los PIR hemos escrito los geó-

\footnotetext{
${ }^{2}$ Ley 15/2001, de 14 de diciembre, del Suelo y Ordenación Territorial de Extremadura (LSOTEX). Sitúa los Proyectos de Interés Regional (PIR) en el tercer y último escalón entre los instrumentos de ordenación territorial: Directrices de Ordenación Territorial (DOT), Planes Territoriales (PT) y PIR (arts. 60 a 65). Decreto 7/2007, de 23 de enero, por el que se aprueba el Reglamento de Planeamiento de Extremadura (DOE, núm. 12, de 30-01-2007). Resulta inconcebible intentar promover una actuación que afecta a toda la región y especialmente a la comarca y a los dos términos municipales sin unas directrices de ordenación jerárquica superior al planeamiento municipal.

${ }^{3}$ El artículo 60 de la LSOTEX, en su redacción inicial (ley 15/2001, de 14 de diciembre), determinaba que «Los Proyectos de Interés Regional ordenan y diseñan, con carácter básico y para su inmediata ejecución, las obras a que se
}

grafos $^{4}$ y los expertos en derecho urbanístico (Corchero y Sánchez, 2014), porque dan para rato. A nuestro juicio, son instrumentos de presunta planificación regional, porque siendo simples proyectos se inmiscuyen en el planeamiento urbanístico de exclusiva competencia municipal ${ }^{5}$. Como técnica de planificación urbana han demostrado ser un desastre, porque pretenden desarrollar suelo contra natura, sin planeamiento general previo y, lo que es peor, a espaldas del mismo ${ }^{6}$. Mediante este sistema, terrenos clasificados como suelos no urbanizables (SNUR) por el planeamiento urbanístico pueden convertirse por arte de magia en suelos urbanizables (SUR) o en urbanos (su), generándose enormes plusvalías privadas con la reclasificación, sin reversión pública a la colectividad, con lo que su «interés regional» y su declaración de buen fin social resultan de difícil justificación. A juzgar por las experiencias, estas operaciones han quedado reservadas sólo para grandes empresas que gozan de información privilegiada.

A los efectos urbanísticos oportunos, para la aprobación inicial del PIR (DOE, núm. 133, de 14-11-2006), fueron necesarias la reclasificación y la reordenación previa de los terrenos de la isla (ubicados en los suelos no urbanizables de los municipios de El Gordo y Berrocalejo), aprobadas el 9-10-2006 por la Agencia Extremeña de la

refieran, pudiendo comprender terrenos situados en uno o varios términos municipales y desarrollarse en cualquier clase de suelo, con excepción de la del suelo no urbanizable protegido» por el planeamiento municipal vigente. Por efecto de la promulgación de la Ley 6/2002, de 27 de junio, de Medidas de Apoyo en Materia de Autopromoción de Viviendas, Accesibilidad y Suelo, dicho art. 60 de la LSOTEX fue objeto de modificación en el sentido de que los PIR «deberán ser compatibles con la protección que, al margen del planeamiento municipal, dispensen al suelo en que se ubiquen las leyes de defensa del medio ambiente, del patrimonio histórico y demás leyes sectoriales». En consecuencia, la interpretación correcta del art. 60 de la LSOTEX es la de que los PIR pueden ubicarse en cualquier clase de suelo, con excepción de aquellos que tengan asignada una protección especial, bien por el propio planeamiento municipal, bien por las normas sectoriales, pues lo contrario constituiría una vulneración de las facultades de clasificación urbanística del suelo que, conforme a lo dispuesto por el art. 8 de la misma norma, corresponden en exclusiva a los municipios, al señalar que «El Plan General Municipal clasifica el suelo de su entero ámbito en los términos de esta ley, mediante adscripción de los terrenos a una de las clases y, en su caso, categorías de suelo urbano consolidado y no consolidado, suelo urbanizable y suelo no urbanizable común y de especial protección», competencia exclusiva que, por otra parte, ha sido reconocida reiteradamente por nuestra jurisprudencia (sTs de 9 de febrero de 1994, sTC 11 de julio de 2001, etc.).

4 A.-J. Campesino Fernández (2006): «Los PIR: intromisión en el municipio». El Periódico Extremadura, Cáceres, 1 de septiembre.

5 Véase el artículo de V. Jiménez y A.-J. Campesino (2015): «Proyectos de (Dudoso) Interés Regional: intromisión en la política municipal de vivienda en Extremadura». Aceptado por el Boletín de la Asociación de Geógrafos Españoles, y en prensa.

${ }^{6}$ Antecedentes extremeños de este «urbanismo sin planeamiento previo» los encontramos en las promociones acogidas a la «ley del Kilómetro», como el Residencial Universidad en la ciudad de Cáceres, con 550 viviendas construidas sobre suelo no urbanizable de protección montaña, sometido a proceso de judicialización, por manifiesta ilegalidad consentida desde la Junta y el Ayuntamiento. 


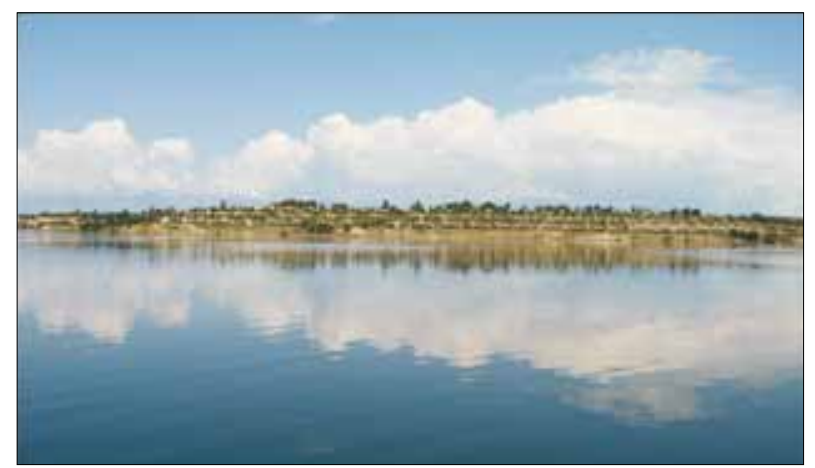

FIG. 8. La parcelación en bancales y la implantación de los edificios en sus parcelas no alteran significativamente el perfil de la isla. Fuente: A.-J. Campesino.

Vivienda, el Urbanismo y el Territorio de la Junta de Extremadura. Ambos minimunicipios, abandonados de la mano de Dios en el extremo oriental de la provincia de Cáceres, tuvieron que modificar a toda prisa su planeamiento urbanístico para dar cabida al proyecto que se iba a desarrollar, a caballo entre ambos términos municipales en suelo rústico totalmente alejado de ambos núcleos de población, que difícilmente podría ser clasificado de urbanizable.

El Gordo, que contaba con un Proyecto de Delimitación del Suelo (PDSU, 1985) ${ }^{7}$, incapaz de ordenar el suelo no urbanizable del término municipal para dar cobertura legal a la urbanización de la isla de Valdecañas, fue obsequiado con un Plan General Municipal (PGM), redactado por Rueda y Vega Asociados, S. L., en menos de dos años ${ }^{8}$. Hubo una segunda aprobación definitiva de «Homologación del PGM de El Gordo para adecuarlo a los preceptos modificados de la LSOTEX» y justificar la declaración de proyecto de interés regional. En consecuencia, se tuvo que modificar el PGM recién aprobado para adaptarlo a la modificación de los artículos 60 y 61 de la LSOTEX (ley 9/2011), que favorecía la construcción de viviendas en complejos turísticos. Por su parte, Berrocalejo dispo-

\footnotetext{
7 PDSU de El Gordo, redactado por el arquitecto Francisco Claros Vicario. Tramitación: aprobación inicial, de 23-07-1985 (BOPC de 16-12-1985). Aprobación definitiva, de 11-07-1986 (BOPC de 25-07-1986). Tuvo después dos modificaciones puntuales, que no afectaron a la zona de estudio.

${ }_{8}^{8}$ PGM de El Gordo. Tramitación meteórica: aprobación inicial de 25-09-2008 para información pública (DOE de 17-10-2008), aprobación provisional de 10-102009 (no publicado en el $D O E$ por error) y aprobación definitiva por la Comisión de Urbanismo y Ordenación del Territorio de Extremadura (CUOTEX) de 15-032010 (DOE de 25-05-2010). «Homologación del PGM de El Gordo para su adecuación a los preceptos modificados de la LSOTEX», con aprobación inicial, del 07-062011, para la información pública (DOE de 13-07-2011) y acuerdo de la CUOTEX de aprobación definitiva (DOE de 04-11-2011).
}

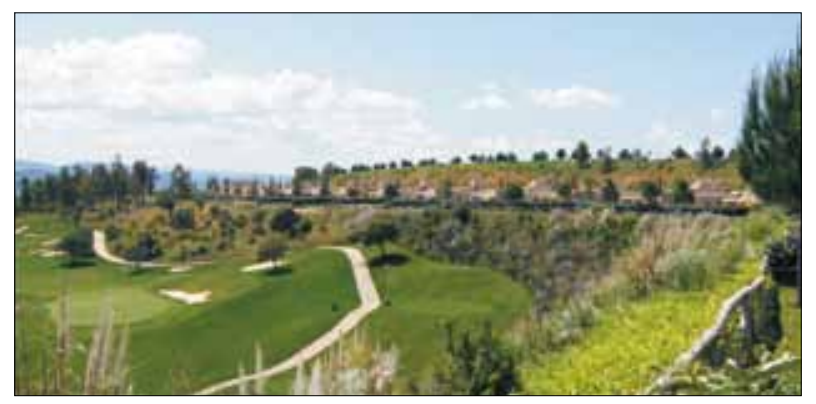

FIG. 9. Villas en bancales, sin superar el perfil de la isla. En este lado de la isla, el primer nivel (próximo a la orilla) es de servidumbre pública; el segundo es el campo de golf (coincidiendo con las vaguadas) y encima van los bancales de las villas, coronando la isla la topografía y la vegetación. Fuente: A.-J. Campesino.

nía también de un PDSU $(1985)^{9}$, que, como en el caso anterior y a idénticos efectos oportunos, fue ascendido a Plan General Municipal (PGM) ${ }^{10}$, para dar asimismo cobertura legal al proyecto Marina Isla de Valdecañas, considerado entonces la punta de lanza de la estrategia del turismo de embalses en Extremadura.

Da gusto ver con qué celeridad se tramita la aprobación del planeamiento cuando corre prisa a la Administración y cómo se evidencia la «perversión» administrativa para modificar ya no sólo el planeamiento, sino hasta la ley del Suelo a capricho del poeta. Supeditar planes a proyectos y retorcer el planeamiento hasta que los proyectos encajen a calzador vienen siendo prácticas hispanas extendidas desde mediados de los años ochenta, con menosprecio del urbanismo como función pública, comenzando por las administraciones presuntamente competentes y siguiendo por los promotores inmobiliarios indisciplinados.

Y quedaba por resolver el asunto medioambiental, porque, como indicamos con anterioridad, el territorio de intervención contaba ya con declaración de zona de especial protección de aves (ZEPA Embalse de Valdecañas, ES0000329) y lugar de importancia comunitaria (LIC Márgenes de Valdecañas, ES4320068), integrados en la Red Natura 2000, como zonas protegidas a instancias de

\footnotetext{
9 PDSU de Berrocalejo, redactado por el arquitecto Carlos-Cándido Fraile Casares. Tramitación: aprobación inicial, de 23-07-1985 (BOPC, de 16-12-1985). Aprobación definitiva, de 11-07-1986 (BOPC, de 24-07-1986). Sin modificaciones posteriores. Tuvo normas subsidiarias municipales, redactadas por el arquitecto Francisco Fernández Castello, sometidas a información pública, solamente publicada en prensa (10-07-1996) y abandonadas en su redacción.

${ }^{10}$ PGM de Berrocalejo, redactado por la arquitecta Inmaculada García Sanz. Tramitación: aprobación inicial, de 15-10-2009 (DOE, de 30-10-2009); aprobación provisional, de 06-03-2012, publicada tres veces (DOE 20-03-2012, 11-05-2012 y 13-12-2012, por haber introducido cambios estructurales relevantes en el documento inicial) y aprobación definitiva, de 30-05-2013, con acuerdo de la CUOTEX, publicado en DOE 26-09-2013).
} 
FIG. 10. Imagen aérea oblicua de la isla, vista desde el Sur. Fuente: El País.

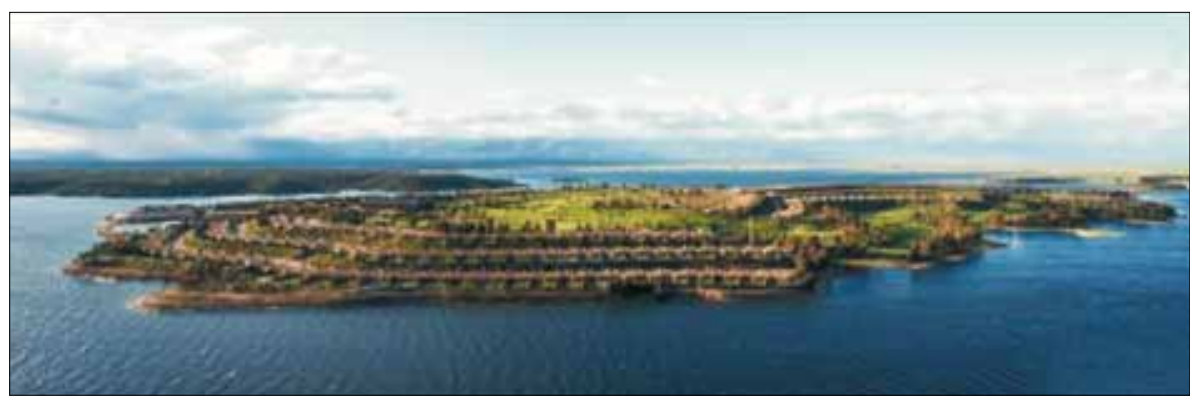

la propia Junta de Extremadura. Para obviar este «mínimo escollo», la Dirección General de Medio Ambiente de la Junta de Extremadura, por resolución de 2 de marzo de 2007 (DOE, núm. 31 de 2-3-2007), declaró de «impacto ambiental favorable» la operación urbanística del PIR, argumentando que «el proyecto puede ser compatible con los valores ambientales presentes en la zona de actuación y con el nivel de protección existente, y que garantiza que la afección a la Red Natura 2000 es prácticamente insignificante, y el desarrollo del proyecto es compatible con la conservación de los valores que dieron lugar a la declaración como ZEPA».

En síntesis, que la zona no tenía un valor ambiental tan extraordinario como para impedir la construcción del complejo y que, como era demasiado tarde para sacar los terrenos protegidos de la legislación medioambiental europea (porque ahora resultaban un estorbo), pues al igual que se forzaba la planificación regional con un PIR y se revisaban a capricho los planeamientos municipales, costaba poco hacer lo propio con un informe de sostenibilidad ambiental (ISA) favorable. Para la política ambiental extremeña, que ha llegado a proteger 1.300 .000 ha, un $34 \%$ del suelo regional, sin fundamento razonado en muchos casos y sólo para dar cancha a los ecologistas y presumir de región impoluta sin afecciones negativas de la industrialización, resulta que a la hora de acoger un proyecto de calidad como el complejo turístico Marina Isla de Valdecañas y declararlo PIR, éste chocaba contra el ultraproteccionismo que ella misma había promovido.

Por ello, para permitir la construcción del complejo turístico de lujo con su licencia preceptiva, se coaligaron a favor todas las administraciones: la Agencia Extremeña de la Vivienda, el Urbanismo y el Territorio reclasificó y recalificó los terrenos de la isla; la Comisión de Urbanismo y Ordenación del Territorio de Extremadura (cuOTEX) otorgó al expediente el visto bueno el 8 de marzo de 2007; la Dirección General de Medio Ambiente santificó la intervención con impacto ambiental favorable, y el presidente Juan Carlos Rodríguez Ibarra estampó su firma en el decreto 55/2007, de 10 de abril, de aprobación definitiva del PIR Marina Isla de Valdecañas por el Consejo de Gobierno de la Junta de Extremadura, publicado en el DOE de 17-4-2007. Como las restantes confederaciones hidrográficas, convertidas en reinos de taifas, que informan el planeamiento cuando quieren, porque lo suyo es el silencio administrativo, en este caso la Confederación Hidrográfica del Tajo, enemiga acérrima de la navegación en los embalses, porque molesta a las grandes compañías hidroeléctricas, no tuvo reparos en regular el caudal del río para que la empresa realizara las grandes obras de infraestructuras (movimientos de tierra, desmontes, terraplenes, depuración y vertido), en autorizar la navegación en el embalse de Valdecañas, en permitir la construcción del dique para la playa artificial, en no proponer otras alternativas que la de la promotora, ni en sopesar las incidencias ambientales. Y, naturalmente, la aquiescencia absoluta de «Bienvenido Mr. Marshall», por parte de los alcaldes de El Gordo y Berrocalejo.

Todo un dislate administrativo en materia de ordenación del territorio, urbanismo, patrimonio y medio ambiente para facilitar la construcción del complejo turístico en suelo no urbanizable protegido ${ }^{11}$, con inversión multimillonaria por parte de una empresa solvente y acreditada por sus urbanizaciones del litoral onubense. Un buen proyecto, frustrado por fallos en cadena en el sistema extremeño de planificación regional, planeamiento urbanístico, gestión y disciplina. La sinergia turística privada-pública parecía lógica y el interés regional del proyecto resultaba evidente para todos, menos para los ecologistas, claro, que pusieron el grito en el cielo.

\footnotetext{
${ }^{11}$ La ingeniería jurídico-urbanística de la Junta de Extremadura para tratar de urbanizar el suelo no urbanizable y legalizar, de paso, las construcciones ilegales plantadas en el mismo, explica los fallos judiciales en contra y las fracasadas modificaciones de la LSOTEx, ajena a la realidad urbanística y territorial de Extremadura: decreto 178/2010, de 13 de agosto, sobre calificación urbanística en el SNUC y SNUP (DOE, número 160, de 19-08-2010). Ley 9/2010, de 18 de octubre, de Modificación Parcial (1.a) de la LSOTEX (DOE, núm. 202, de 20-10-2010).
} 


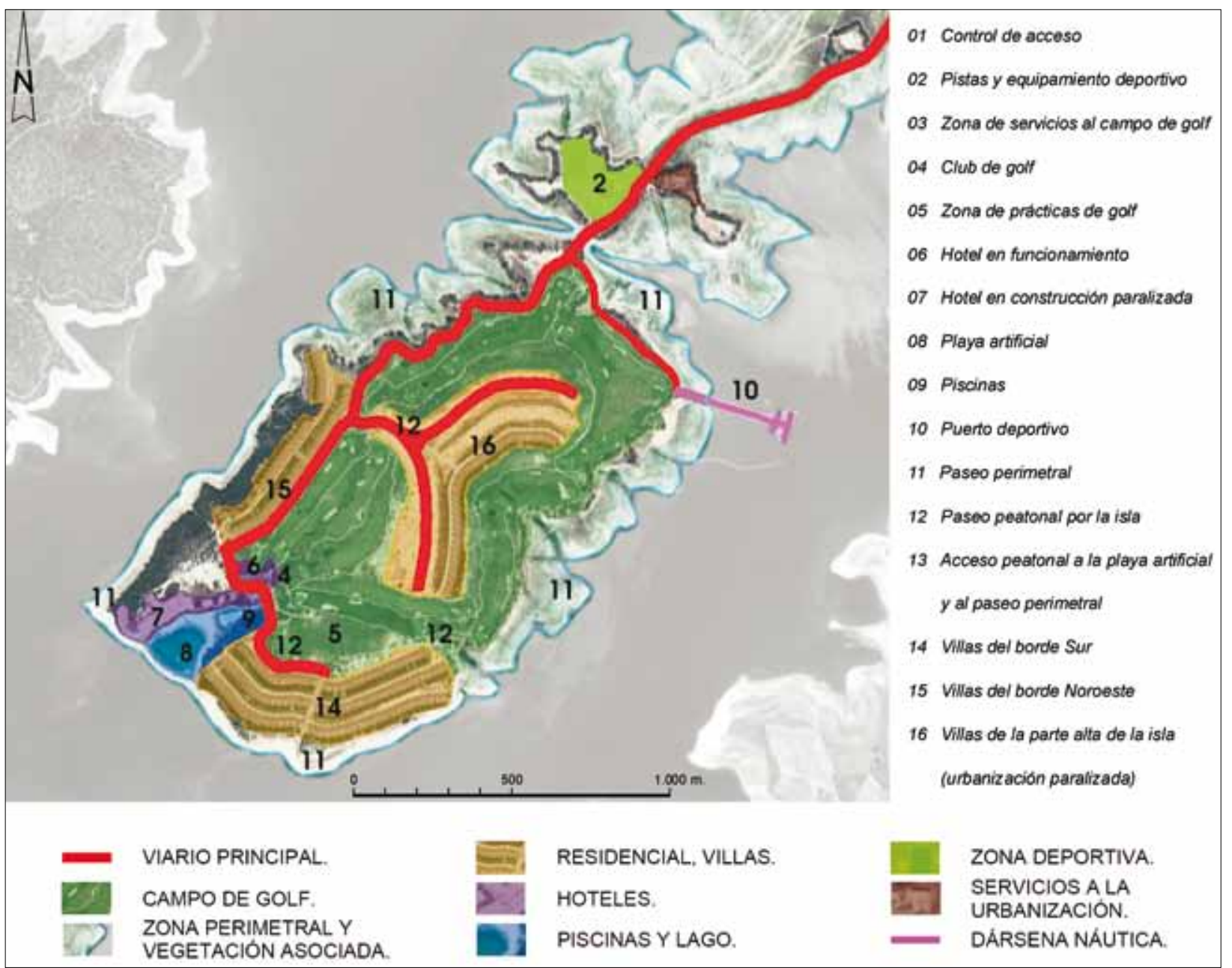

FIG. 11. Análisis de la zonificación de la urbanización de la isla. Elaboración propia.

\section{ECOLOGISMO VS. URBANIZACIÓN E INGENIERÍA LEGAL}

El proyecto turístico-hotelero de lujo no fue asumido por los Ecologistas en Acción del Campo Arañuelo, por la creación ilegal de un resort de lujo en suelo no urbanizable y por la afección ambiental a la ZEPA y LIC, que vulneraba presuntamente las directrices europeas de protección ambiental de la Red Natura 2000. Sin embargo, a estos argumentos razonables se unieron otros, absolutamente demagógicos, como ser una urbanización especulativa para «ricos» de espaldas a la población local (pobre); impedir el desarrollo sostenible de la zona (resulta que los municipios de El Gordo y Berrocalejo han multiplicado sus efectivos humanos y las ofertas de empleo) y «privatizar» un suelo rústico (?), que hasta el momento de su venta no era sino privado.

Con fecha 16 de marzo de 2007, la Asociación para la Defensa de la Naturaleza de Extremadura (ADENEX) denunció a la Junta de Extremadura ante la Unión Europea por aprobar el macrocomplejo turístico, concederle declaración de impacto ambiental favorable y otorgar la declaración de PIR a su construcción sobre un espacio natural protegido, contraviniendo el derecho comunitario de la Unión Europea en materia de especies y hábitats, con el agravante de que a menos de doscientos metros de su extremo sureste se encontraba el límite del LIC Márgenes de Valdecañas. Ante el Tribunal Superior de Justicia de Extremadura (TSJEX), el grupo Ecologistas en Acción del Campo Arañuelo presentó un recurso contencioso- 


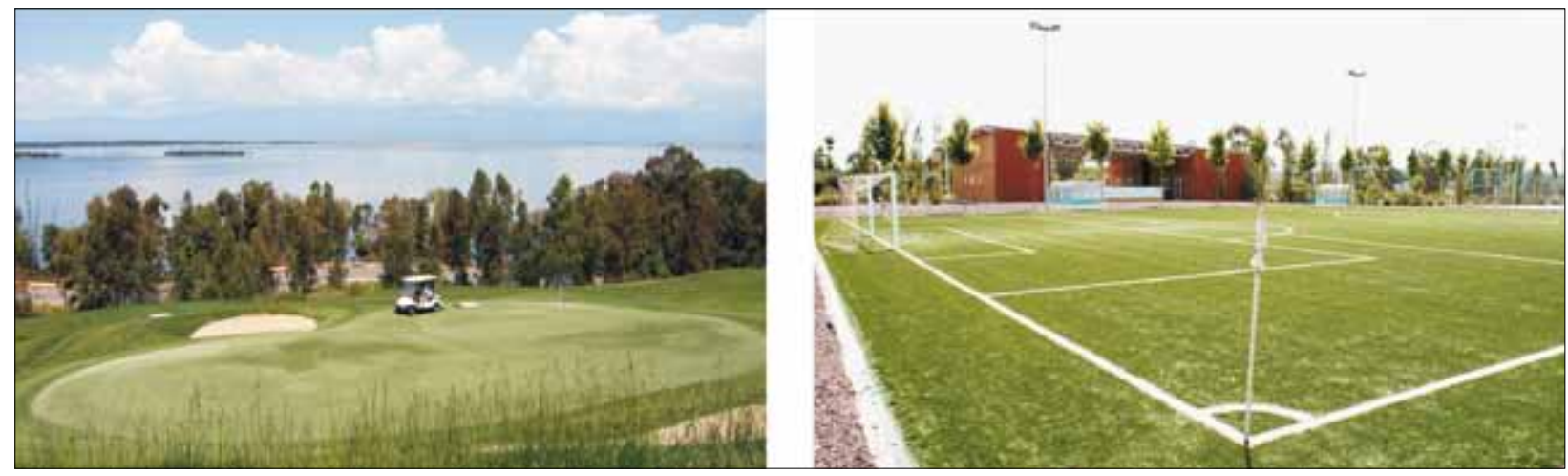

FIG. 12. Campo de golf y campo de fútbol. Fuente: A.-J. Campesino.

administrativo contra la Junta de Extremadura, los ayuntamientos de El Gordo y Berrocalejo y la empresa promotora del proyecto, Marina Isla de Valdecañas, S. L., impugnando la declaración del proyecto como PIR y argumentando que vulneraba las legislaciones extremeña y estatal de suelo, por cuanto no era legal reclasificar ni recalificar un suelo para un complejo turístico privado, de nulo interés social, sin valoración suficiente del daño ambiental y sin que el informe de sostenibilidad ambiental presentase otra alternativa de ubicación, próxima a los núcleos consolidados, conforme a los principios urbanísticos básicos.

Resulta muy importante destacar que las denuncias de las asociaciones ecologistas ante el Parlamento Europeo no obtuvieron el éxito deseado, por cuanto la Eurocámara emitió una respuesta contraria a las mismas el 21 de septiembre de 2007:

A la luz de la información disponible, la Comisión no ve pruebas de que el mencionado proyecto vaya a repercutir negativamente de manera significativa sobre el estatuto de conservación de las características por las que los citados lugares fueron incluidos en la Red Natura 2000 [...], [concluyendo] que no ve indicios de que la legislación comunitaria esté siendo infringida actualmente y, por tanto, no prevé adoptar más medidas al respecto.

La Sala de lo Contencioso-Administrativo del TSJEX, por sentencia número 196/2011, de 9 de marzo, dio trámite, estimó el recurso ecologista y declaró nulo el proyecto y el decreto de aprobación del mismo como proyecto de interés regional (PIR), que permitió la urbanización de la isla. Por un lado, al carecer esta iniciativa empresarial de falta de justificación para ser catalogada como PIR y no poder considerarse de utilidad pública e interés social, y por otro, al estimar que las 133,7 ha de la isla debían ser consideradas como suelo no urbanizable de especial protección, por encontrarse dentro de la ZEPA de Valdeca- ñas. La sentencia declara con nitidez la falta de ajuste al ordenamiento jurídico:

Cuando terrenos como los de los autos — integrados en la Red Natura 2000 - están sometidos a un régimen especial de protección por la legislación sectorial, tienen la consideración de suelo no urbanizable de protección especial, cuya clasificación es reglada, pues si concurren los valores que se pretenden salvaguardar, su carácter como suelo no urbanizable se impone por ministerio de la ley y su clasificación como tal resulta obligada para el planificador. A criterio del juzgado es justamente lo que pretende hacer el proyecto de interés regional, aprobado por decreto que se recurre, en contra de la prohibición que se impone por imperativo legal.

En consecuencia, la sentencia ordena «la reposición de los terrenos [...] a la situación anterior a la aprobación de dicho proyecto y los actos que se hubieran ejecutado con fundamento en el mismo».

Sólo tres semanas después de emitida la sentencia (30-03-2011), el Parlamento de Extremadura (gobernado aún por el PSOE y en connivencia con el PP), modificó el artículo 11 de la ley del Suelo (LSOTEX) ${ }^{12}$ para permitir la urbanización de los espacios integrados en la Red Natura 2000, específicamente la isla de Valdecañas, bajo el criterio de que el proyecto favorecería la creación de empleo en la región y en los municipios colindantes. Con el nuevo argumento legal en la mano, la CUOTEX emitió una resolución de 28 de julio de 2011 por la que se aprueba definitivamente la homologación del PIR de Valdecañas a la nueva Ley 9/2011, publicada en el DOE de 26-09-2011 ${ }^{13}$.

\footnotetext{
12 Ley 9/2011, de 29 de marzo, de Modificación Parcial (2..) de la LSOTEX (DOE, núm. 62, de 30-03-2011).

${ }_{13}$ Resolución de 28 de julio de 2011, de la Comisión de Urbanismo y Ordenación del Territorio de la Junta de Extremadura, por la que se aprueba definitivamente la homologación del Proyecto de Interés Regional, denominado «Complejo Turístico, de Salud, Paisajístico y de Servicios Marina Isla de Valdecañas. Cliente: Marina Isla de Valdecañas. Localización: El GordoBerrocalejo (Cáceres). Superficie: $1.336 .017 \mathrm{~m}^{2}$. Edificabilidad: $117.900 \mathrm{~m}^{2}$.
} 

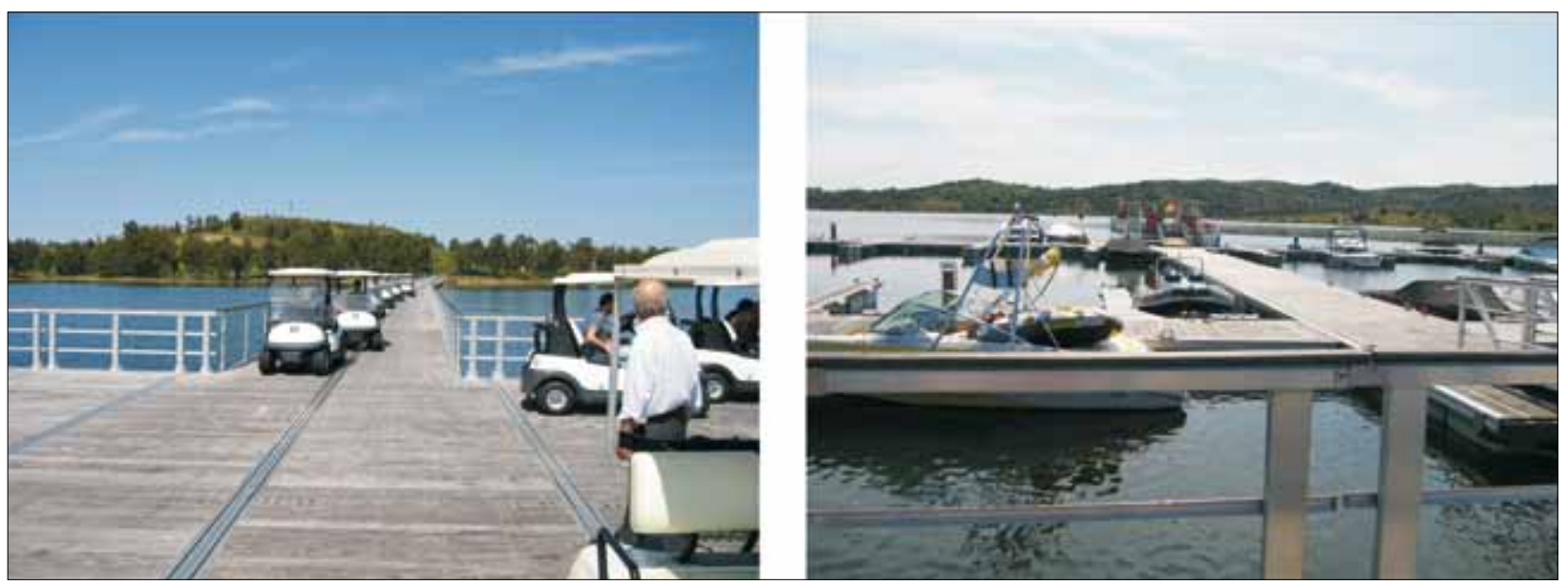

FIG. 13. Dársena náutica con pantalán para atraques. Fuente: A.-J. Campesino.

El TSJEX considera que esta reforma no tiene eficacia retroactiva y que, por tanto, no es aplicable al PIR de Valdecañas, ni que tampoco afecta a esta iniciativa empresarial el proceso de homologación urbanística, aprobado en septiembre de 2011, y que se incluye en la disposición adicional de la reforma, advirtiendo a la Junta, a los ayuntamientos de El Gordo y Berrocalejo y a la empresa Marina Isla de Valdecañas de que el cambio normativo no es suficiente, porque la legislación aplicable es la que se utilizó con anterioridad para autorizar la construcción del complejo turístico. De manera que una modificación de la ley del Suelo, interesada y a posteriori no puede utilizarse para rebatir las dos sentencias que el TSJEX dictó en 2011 y que fueron recurridas por las partes implicadas ante el Tribunal Supremo (TS).

Por auto dictado el 13 de enero de 2012, el TSJEX ordenó la paralización de las obras, la prohibición de ocupar las instalaciones hasta que el ts se pronunciara y la ejecución provisional de la sentencia, condicionada a que los ecologistas demandantes depositaran en el juzgado una fianza de 41 millones de euros, para cubrir costes y daños de la empresa promotora, derivados de la paralización de las obras y de la explotación, norma habitual en este tipo de procedimientos, pero inalcanzable para los ecologistas.

Por sentencia de 29 de enero de 2014, conocida el 6 de febrero, la Sala de lo Contencioso-Administrativo del Ts desestimó los recursos presentados por la Junta de Extremadura, los ayuntamientos de El Gordo y Berrocalejo

Uso: residencial, hotelero y deportivo. Sistema de actuación: compensación. Presupuesto de actuación: 28.735.615,00€. y la empresa Marina Isla de Valdecañas contra la sentencia del TSJEX y confirmó la sentencia de este tribunal que declaraba nulo el PIR para la construcción del complejo turístico-deportivo y de ocio, argumentando que «la jurisprudencia, puesta en relación con la normativa comunitaria europea sobre protección ambiental, establece que cuando unos terrenos están sujetos a algún régimen especial de protección sectorial resulta preceptiva su exclusión del desarrollo urbano y su clasificación por el planeamiento como suelo no urbanizable».

Y el problema radica en que cuando los PIR pretenden actuar como instrumentos de ordenación urbanística, suplantando a los planes generales municipales, deben someterse a las reglas esenciales de éstos, sin anteponerse a ellos y respetando los estándares mínimos que contempla el artículo 74. En el caso de Valdecañas, ni se cumplen (ausencia de vivienda de promoción pública), ni se justifican, ni se razonan, porque la finalidad del PIR fue la de permitir la explotación de un complejo turístico de lujo, con exquisitas instalaciones complementarias y costosas viviendas de segunda residencia, aprovechando las condiciones naturales del embalse y la magnífica renta de situación.

Es llamativo que los dos partidos políticos, que no se ponen de acuerdo para casi nada, mantengan el mismo criterio cuando se trata de irregularidades urbanísticas: el Gobierno de Extremadura cambia a manos del PP y hereda, naturalmente, el problema. Se dispone el 7 de febrero de 2014 a impugnar ante el Tribunal Constitucional (TC) la sentencia del ts que había declarado ilegal el complejo turístico. Esgrime como argumento que la urbanización de los terrenos protegidos se llevó a cabo tras la aprobación unánime por la Asamblea de Extremadura 


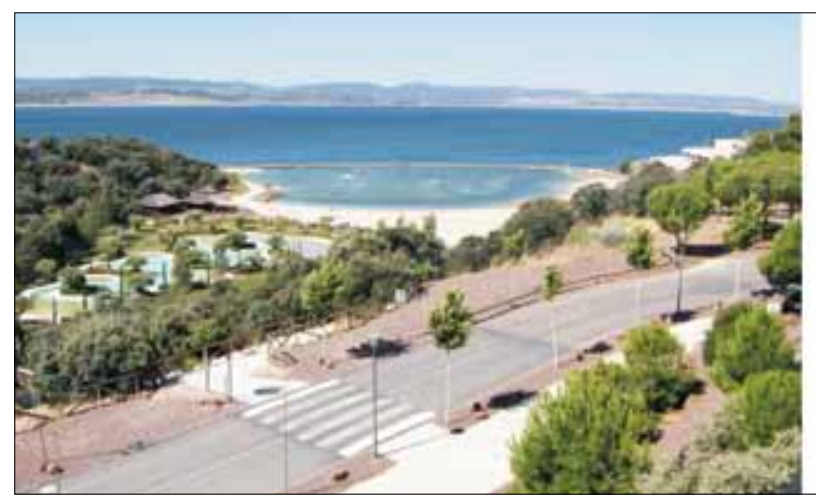

FIG. 14. Red viaria interna. Fuente: A.-J. Campesino.

del complejo turístico Marina Isla de Valdecañas, declarado PIR en abril de 2007, y que para ello el Gobierno socialista modificó posteriormente, en dos ocasiones (2010 y 2011), la Ley del Suelo y Ordenación Territorial de Extremadura. Una reclamación al TC que no se sostiene jurídicamente, por cuanto el Ts en su sentencia está aplicando normas europeas y estatales de protección, a las que pretende sobreimponerse la Junta de Extremadura, retorciendo sus normas de rango autonómico.

Tampoco sirve, como argumento político, descalificar el proceso gestor de «chapuza socialista» por parte del Partido Popular, por cuanto ellos mismos en la oposición apoyaron la realización del proyecto «con sentido de región».

\section{V. ¿LIQUIDACIÓN POR DERRIBO?}

Al declarar ilegal el complejo turístico, la sentencia del Ts condena a la restitución de los terrenos a su prístino estado (isla desierta con eucaliptos), lo que en román paladino significa demoler la urbanización ya realizada, con un coste de derribo de 34 millones de euros, sin prever siquiera dónde se tirarán los escombros... En consecuencia, unos eucaliptos plantados durante el franquismo se habrían convertido en los más protegidos de Extremadura...

De manera que el mayor complejo turístico de la región (donde se dan cita los fines de semana los políticos, banqueros, empresarios y futbolistas más conocidos del país), que por los conflictos jurídicos sólo ha desarrollado la primera fase (sesenta por ciento del total previsto) con inversión de ciento veinte millones de euros, tiene que ser derribado.

La relación de elementos a demoler es la siguiente: 185 villas unifamiliares de lujo (con precio medio de quinientos mil euros), hotel de cuatro estrellas y cien ha-

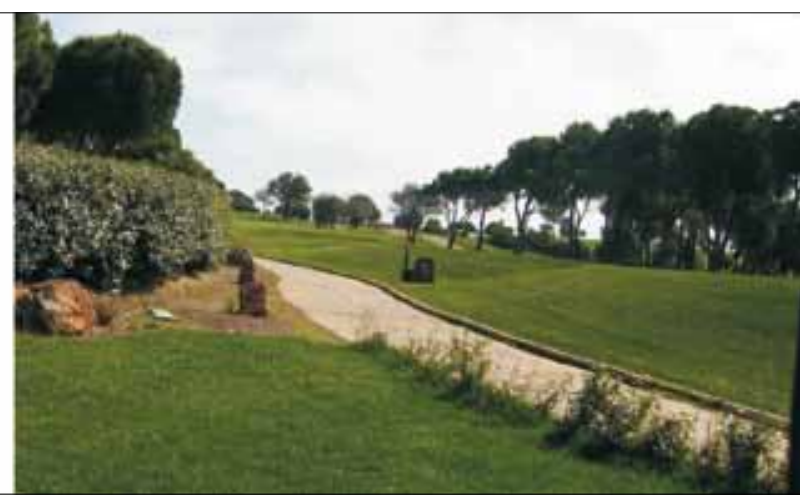

bitaciones (que para más inri recibió un millón de euros de subvención europea para desarrollo de zonas deprimidas), campo de golf de 18 hoyos, instalaciones deportivas y de ocio (campos de fútbol, siete pistas de tenis y pádel, squash, circuito de bicicletas, pistas polideportivas, dársena náutica con 87 atraques, playa artificial, piscinas con club social...) e infraestructuras (red viaria de carretera de acceso de $1,8 \mathrm{~km}$; planta de abastecimiento y potabilización de aguas; saneamiento y sistema de tratamiento de aguas residuales; electrificación y subestación; instalación y suministro de gas centralizado y dique de hormigón para la contención de la playa artificial). También hay que demoler el Hotel Medical-Spa ${ }^{14}$ de cinco estrellas en construcción.

Ante la orden de ejecución de la sentencia, el sainete político es total. Gobierno del PP y oposición, ahora del PSOE, dudan entre el recurso al TC o la negociación con los ecologistas, porque cumplir el fallo que obliga a demoler las construcciones y arrasar el arbolado para devolver los terrenos al estado original generaría impactos negativos en la ZEPA y, sobre todo, porque ni PSOE ni PP quieren asumir la responsabilidad de la construcción, con sus cuantiosas indemnizaciones, ni el coste del derribo.

Por su parte, la empresa promotora alega la inexistencia de protección ambiental alguna sobre la zona cuando decidió abordar el proyecto, lo que contradice una notificación de la Junta de Extremadura de noviembre de 2005, recordándole que es una zona ZEPA. Asimismo, hay que considerar los daños colaterales. La primera sentencia en contra del TSJEX obligó a la empresa a firmar una escritura

\footnotetext{
${ }^{14}$ El Hotel Medical-Spa de cinco estrellas en proceso de construcción no se terminó debido a la crisis económica y a los fallos judiciales, aprobándose una modificación puntual del PGM de El Gordo (sector SE-05, que comprende la isla de Valdecañas), para trasformar la estructura en apartamentos y evitar que quedase el esqueleto visto.
} 


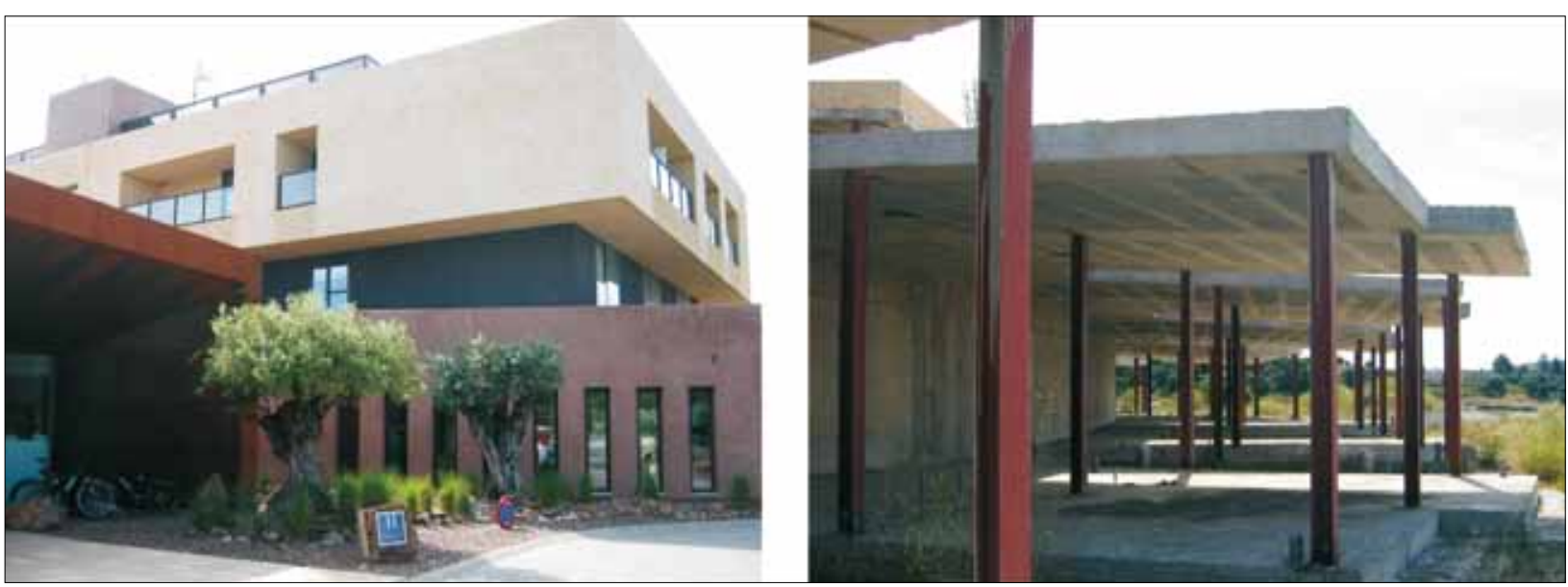

FIG. 15. Hoteles: Husa Golf de cuatro estrellas y hotel-spa de cinco estrellas, a medio construir.

de garantía de recompra de las villas (cuyo valor inicial era de 650.000 euros) a los propietarios. La segunda sentencia del ts (que bloqueó la segunda fase constructiva) desató las reclamaciones económicas de bancos, acreedores y propietarios para la devolución de las cantidades adelantadas, lo que forzó a las empresas Marina Isla de Valdecañas, S. L., y Atalaya de Valdecañas, por insolvencia financiera, a presentar el 19 de agosto de 2014 un preconcurso de acreedores en el Juzgado de lo Mercantil número 1 de Sevilla, ciudad donde ambas se encuentran radicadas.

El 16 de octubre de 2014, en un hecho jurídico sin precedentes, el TSJEX convocó a las partes implicadas (Gobierno de Extremadura, ayuntamientos de El Gordo y Berrocalejo, empresa promotora del complejo Marina Isla de Valdecañas, dos comunidades de propietarios de chalés de lujo, Ecologistas en Acción y ADENEX) en la Sala de lo Contencioso-Administrativo, para la designación de un perito de oficio que cuantifique los costes de una posible demolición, así como el pago de las responsabilidades patrimoniales.

La defensa del Gobierno de Extremadura argumenta que devolver la isla a su estado original es «imposible», proponiendo una negociación que no implique la demolición, cuyo coste se estima en 34 millones de euros (la lectura sibilina entre líneas equivaldría a transferir esa cantidad a los ecologistas para que retiren la demanda). El gobierno del PP, que en 2011 había heredado el problema del gobierno socialista, aboga por mantener el complejo para el interés general del pueblo extremeño, defendiendo el medio ambiente, pero también el desarrollo, aprovechando los recursos disponibles, al objeto de que «Extremadura no sea un zoológico, ni un jardín bo- tánico». Desde las instancias políticas de gobierno y oposición se comienza a reconocer, tímidamente, el exceso de proteccionismo ambiental otorgado al territorio extremeño y sus contradicciones, por cuanto si bien las masas de agua de Extremadura otorgan a la región el primer lugar peninsular por kilómetros de costa dulce interior, de gran atractivo económico y enorme potencial turístico, de poco sirve contar con tales recursos de agua embalsada si el exceso de celo protector ambiental impide su conversión en productos turísticos y el desarrollo socioeconómico de los mini-municipios rurales en declive.

Por su parte, la letrada de los ecologistas mantiene que la sentencia de derribo dictada por el ts es clara y que no cabe otra salida que ejecutarla y demoler el complejo, por incumplimiento de la ley del Suelo, al modificar la clasificación del mismo en zonas protegidas, mediante informes administrativos sesgados y tendenciosos que pretendieron maximizar los beneficios y minimizar los impactos ambientales. Argumenta que la creación de puestos de trabajo ha sido mínima y a precios disparatados (1,8 millones de euros de inversión por empleo generado de alta temporalidad). Para los ecologistas, desde que existe el resort de lujo, trece de las catorce especies de anátidas que habitan en la zona en invierno han visto decrecer su población (entre ellos el silbón europeo, el ánade friso y el azulón), especies que entre 2003-2005 y 2012-2014 han dividido sus poblaciones por 13, 116 y 11 , respectivamente. Dicen ellos...

Y queda por tratar el espinoso tema de las responsabilidades patrimoniales, porque en caso de derribo la empresa promotora Marina Isla de Valdecañas, S. L., las exigirá, dado que la obra no es ilegal, al disponer de licencia concedida por la Junta de Extremadura, y los pro- 


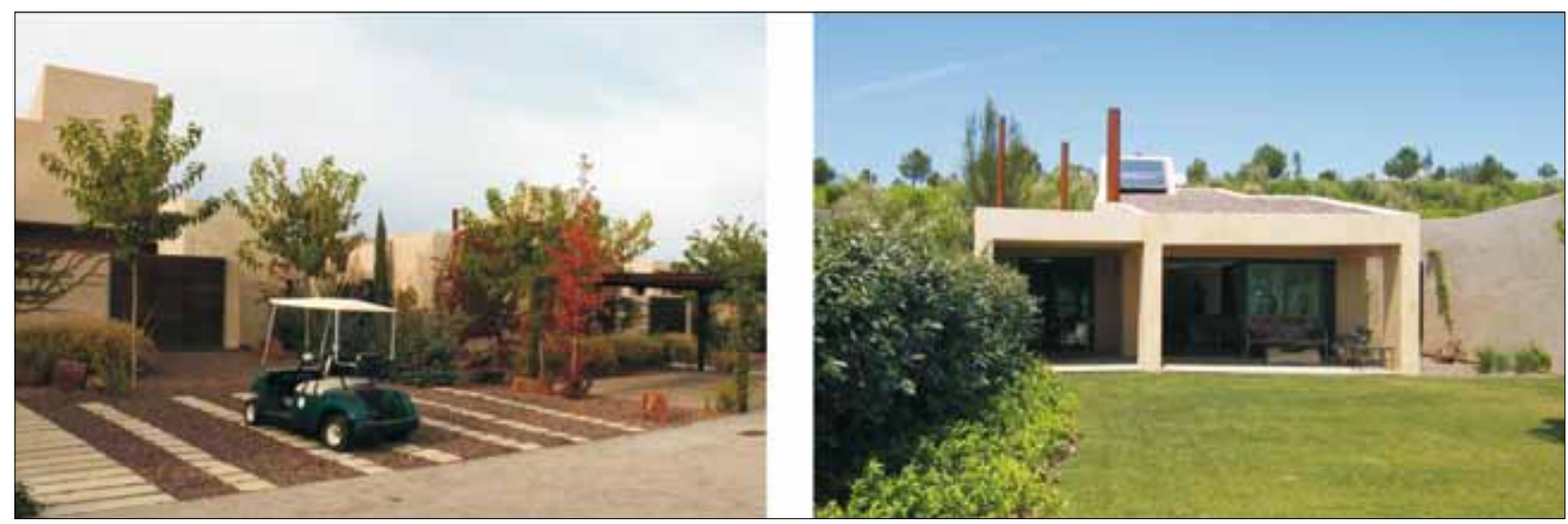

FIg. 16. Tipología de villas unifamiliares. Fuente: A.-J. Campesino.

pietarios de las edificaciones tienen todo el derecho a las indemnizaciones pertinentes.

Ante la falta de acuerdo entre las partes implicadas, el TSJEX resolvió designar peritos que evalúen el estado de la zona protegida anterior a la construcción y tras los informes técnicos decidir si se ejecuta o no la demolición y en qué términos. En respuesta a la petición del Gobierno de Extremadura, el 24 de marzo de 2015 el TSJEX notificó la paralización del derribo del complejo turístico hasta conocer los resultados del informe pericial, encargado por la misma Sala a los técnicos de la Estación Biológica de Doñana (CSIC), para contrastar varios extremos condicionales: si existía justificación razonada para la inclusión de la isla en la ZEPA por ser hábitat de alguna especie de avifauna amenazada de extinción; si la declaración de impacto ambiental estaba motivada, y cuál es, realmente, el impacto de la urbanización sobre el medio ambiente protegido.

Con fecha de 10 de abril de 2015, el Gobierno de Extremadura publicó la «última» revisión puntual... de la LSOTEX $^{15}$.

\section{CONCLUSIONES}

Que el objetivo de Marina Isla de Valdecañas era el beneficio empresarial a partir de una inversión multimillonaria no puede extrañar a nadie y, menos aún, dudar de

\footnotetext{
${ }^{15}$ Ley 10/2015, de 8 de abril, de Modificación de la Ley 15/2001, de 14 de diciembre, del Suelo y Ordenación Territorial de Extremadura. Aprobada por el Pleno de la Asamblea de Extremadura en sesión celebrada el día 12 de marzo de 2015. Boletín Oficial de la Asamblea de Extremadura, VIII Legislatura, núm. 753, 13 de marzo de 2015. Gobierno de Extremadura, Mérida, 32 pp.
}

la contrastada calidad de sus urbanizaciones en la costa onubense. Para ello, la empresa pensó en el potencial turístico de Extremadura, aún por explotar, adquirió suelo, redactó un proyecto solvente, solicitó y obtuvo todos los permisos y licencias para la urbanización, al objeto de aprovechar los recursos paisajísticos del territorio y su renta de situación, contribuyendo a su desarrollo y globalización turística internacional.

El problema no es de la iniciativa privada, sino de la Administración regional con todos los departamentos implicados, que en lugar de aprovechar los recursos patrimoniales disponibles, legislando, planificando y gestionando con cultura positiva del territorio, para hacer compatible el desarrollo socioeconómico con el respeto al patrimonio natural y cultural, se enreda ella misma en su propia maraña legal, como hemos puesto de manifiesto en el caso del Complejo Turístico Marina Isla de Valdecañas.

Claro que no puede extrañar, aunque parezca increíble, que después de tres decenios largos de autogobierno, Extremadura carezca aún de modelo territorial, porque la inadecuación de la ley del Suelo al territorio de Extremadura es total, desde su redacción por el equipo de Luciano Parejo, precisando no de parches puntuales al arbitrio del poeta, sino de una total revisión y adaptación al territorio y a la realidad socioeconómica de la Extremadura del siglo XXI. Y no existe modelo territorial, porque las Directrices de Ordenación Territorial (DOT), que deberían haberlo definido hace quince años, aún no se han redactado... De los Planes Territoriales (PT) hay aprobados tres... y de los Proyectos de Interés Regional, ya hemos podido comprobar su credibilidad.

En consecuencia, si los instrumentos de planificación regional (DOT, PT y PIR) son inoperantes, por desidia administrativa, no se puede pretender la ordenación del 

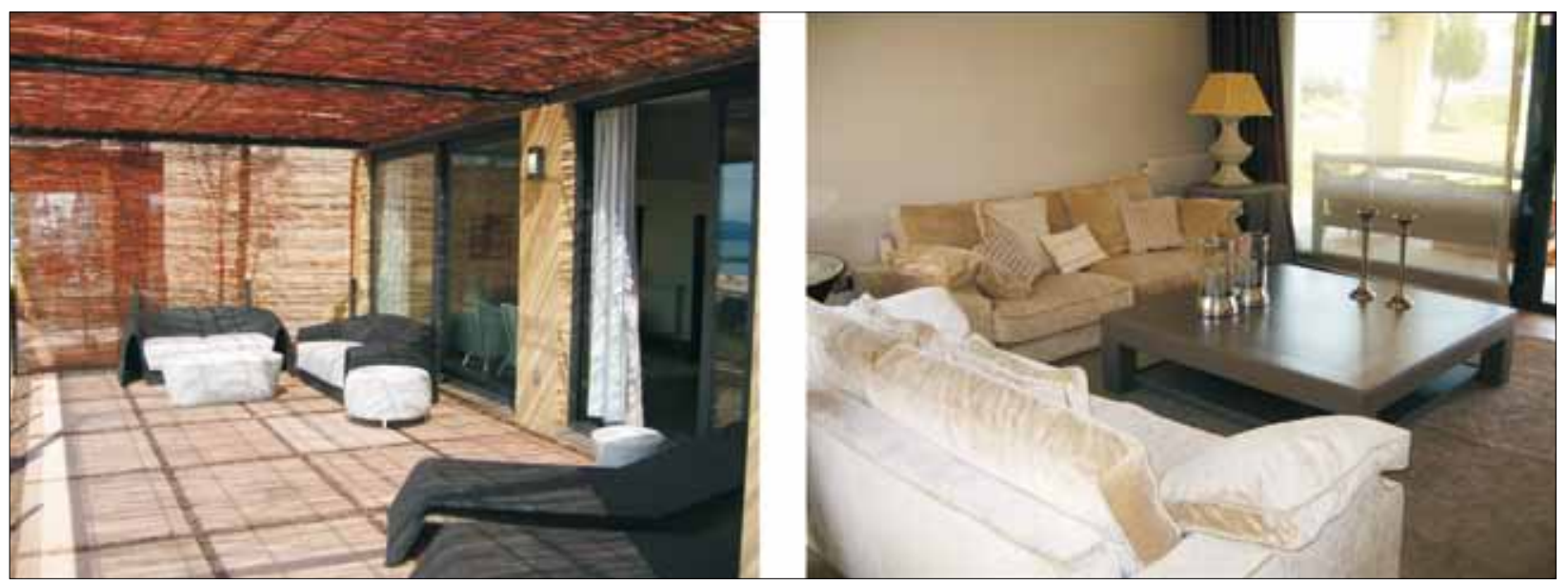

FIG. 17. Porches, pérgolas y diseño interior. Fuente: A.-J. Campesino.

territorio de Extremadura mediante la suma de planes generales municipales inconexos. En quince años de planeamiento, gestión y disciplina (las tres patas del trípode urbanístico, manifiestamente incumplidas a tenor del archipiélago de urbanizaciones ilegales), sólo se han conseguido aprobar 49 planes generales municipales, para el 12,6\% de los 388 municipios de Extremadura. A este ritmo vertiginoso, necesitaríamos 145 años para ver ultimada la absurda imposición de la LSOTEX de que todos los municipios extremeños, con independencia de su tamaño y de su estructura territorial y socioeconómica, tengan que redactar, por decreto, un plan general municipal.

Los paisajes de Extremadura conservan valores naturales de gran calidad ambiental, al no haber sido alterados por procesos de industrialización y urbanización desarrollistas, carencias de las que algunos todavía presumen. Además de constituir un legado patrimonial a proteger para la contemplación beatífica, tienen la consideración de bienes públicos, recursos económicos y productos turísticos. No es sostenible que un tercio de la superficie de Extremadura se encuentre afectada por alguna figura de protección de la naturaleza, hasta alcanzar 1.300.000 hectáreas, lo que constituye un dislate, carente de sentido económico y social y un lastre limitante para el desarrollo regional, fruto, en gran medida, del flirteo político pasado con el falso ecologismo conservacionista «antitodo».

Éste es el caso de la isla de Valdecañas en el embalse de su nombre, cuyos presuntos valores ambientales la hicieron acreedora a ser incluida en la Red Natura 2000. Resulta hilarante que, tras la construcción del embalse de Valdecañas (1956-1963), que sepultó bajo sus aguas ciudades y calzadas romanas, pueblos, vías pecuarias y redes camineras, el hábitat del islote de Valdecañas, totalmente alterado, conservase milagrosamente «valores eternos que proteger». Ha bastado consultar la fotografía aérea del vuelo americano de 1956, previa a la transformación hidráulica, para constatar su estado de erial a pastos con una docena de denostados eucaliptos. Si la experiencia profesional demuestra que buena parte del deterioro y la ruina de los conjuntos históricos patrimoniales fue debida a la excesiva protección otorgada sin criterio a los inmuebles por el planeamiento especial ultraconservador, que hipotecó su rehabilitación, repoblación y regeneración económica, otro tanto ocurre con la clasificación del suelo no urbanizable de especial protección a manta, sin razonamiento alguno, que está limitando los usos agropecuarios tradicionales, sin compensación alguna para los propietarios rurales, y bloqueando los nuevos usos industriales y turísticos del territorio.

Y claro, puestos a desvariar, no hay que ser un experto urbanista para entender que el suelo no urbanizable protegido por sus valores patrimoniales no puede ser urbanizado, ni edificado con instalaciones ajenas al medio agropecuario y forestal, por mucho retorcimiento de la legislación autonómica que se quiera hacer a toro pasado, reinterpretando lo legalmente no interpretable, porque ofende a la inteligencia y motiva los fallos jurídicos en contrario.

Devolver la isla a su estado prístino tendrá que aceptarse como fallo judicial, pero el Ts dictó una sentencia de discutible cumplimiento por razones obvias de irreversibilidad.

Si proyectos turísticos de calidad, como el de Marina Isla de Valdecañas, construido por una empresa de contratada solvencia urbanística (Marina Isla Antilla, Complejo El Rompido - Cartaya-), con inversión multimi- 


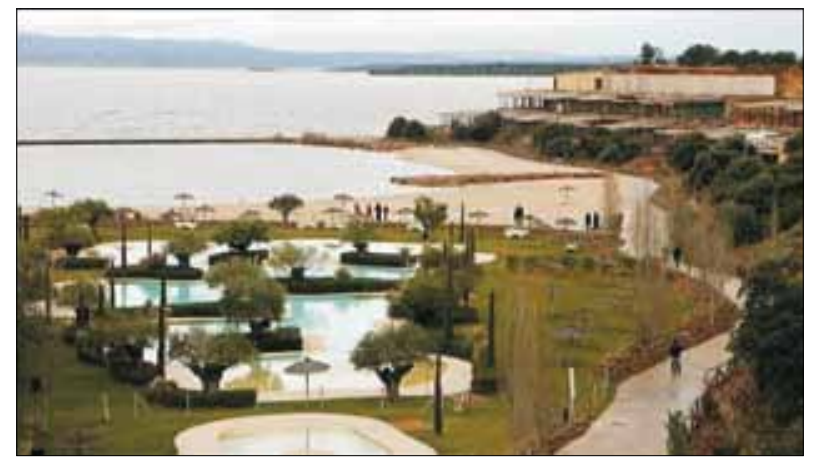

FIG. 18. Piscinas, playa fluvial represada y Hotel Medical-Spa en construcción. Fuente: Empresa MIV.

llonaria, motor de la dinamización económica en tiempos de crisis, no pueden prosperar en Extremadura, entonces tenemos que revisar los parámetros ultraproteccionistas, sinónimos de hibernación social y económica.

El cambio de modelo territorial ha de llevar aparejada la reconsideración del proteccionismo ambiental a ultranza y la descalificación de todas las áreas protegidas sin fundamento razonado, incluido el embalse de Valdecañas, porque tener bloqueado un tercio del suelo de Extremadura como zoológico sin fieras no es de recibo y a las pruebas nos remitimos

¿Qué empresa turística pensará invertir otros doscientos millones de euros en Extremadura? ¿De qué vale promocionar turísticamente la «marca Extremadura»? ¿Qué operatividad tienen los recursos patrimoniales sin traducción a productos turísticos? Interrogantes que lanzamos para que los lectores inteligentes les den las respuestas oportunas.

\section{BIBLIOGRAFÍA}

<http://www.vitruvio-publicaciones.blogspot.com.es/2014 /08/el-caso-de-la-urbanizacion-marina-isla.html>. $<$ https://www.youtube.com/watch?v=esaFGOSZh5g $>$. $<$ https://www.youtube.com/watch?v=k1fIK10dwU0>. $<\mathrm{https}$ ://www.youtube.com/watch?v=k_rQXKlmns $>$. <http://www.lasexta.com/videos-online/programas/ equipo-investigacion/noticias/isla_2014110700227. html>

<http://www.hoy.es/nacional/201407/27/turismo-embalses-modelo-valdecanas-20140727001631-v.html>.
CAmpesino Fernández, A-J. (2010-2012): «Ordenación territorial de la Extremadura democrática», en Cuadernos de Geografía, núm. 47 (El estado de la ordenación del territorio en España [The state of the spatial planning in Spain]). Monográfico, coord.: Francisco Rodríguez Martínez, Instituto de Desarrollo Regional, Universidad de Granada, Granada, pp. 553-581.

- (2014a): «Centros y periferias urbanas: ordenación y desgobierno», en R. C. Lois y Á. Miramontes (eds.). Reflexiones sobre las ciudades y el sistema urbano en tiempos de crisis. Universidad de Santiago de Compostela/Grupo de Geografía Urbana de la AGE, Santiago, pp. 91-117.

- (2014b): «En defensa del complejo turístico Marina Isla de Valdecañas». Diario Hoy (Cáceres), sábado 8 de febrero de 2014, Grupo Vocento, p. 19.

- M. SÁnchez y J. I. Rengifo (2013): «El turismo en Extremadura», en J. M. Coleto, E. Muslera y F. Pulido (eds.). La agricultura y la ganadería extremeñas. Caja de Ahorros de Badajoz, Badajoz, pp. 87-101.

Corchero, M., y L. SÁnChEZ (2014): «El control judicial del urbanismo de interés regional». Práctica Urbanística. Revista mensual de urbanismo, núm. 128, pp. 28-56.

JunTA DE EXTREMAdura (2012): Orden de 11 de diciembre de 2012, por la que se aprueba el Plan de Gestión de la ZEPA Embalse de Valdecañas. Formulario Oficial Red Natura 2000. Mérida.

Mora Aliseda, J.: Impacto socioeconómico de la demolición del complejo Marina Isla de Valdecañas. Informe encargado por el Gobierno de Extremadura. Mérida.

- (dir.). (2014): Gestión de recursos hídricos y aprovechamientos turísticos. Curso Internacional de Verano de la Universidad de Extremadura/Gobierno de Extremadura/Ayuntamiento de Navalmoral de la Mata/ Empresa Marina Isla de Valdecañas.

SAlcedo Hernández, J.-C. (2014): «Patrimonio arquitectónico en el territorio: diagnóstico y propuestas en el caso de Extremadura», en A. J. Campesino y J. M. Jurado (dirs.): Turismo de Frontera III, productos turísticos de la Raya Ibérica. Universidad de Huelva. Resultados del proyecto de investigación CSO201129529-C04, Universidades de Extremadura, Vigo, Huelva y Salamanca. ISBN: 978-84-16061-29-7. 